\section{Влияние подготовки почвы и вида посадочного материала на рост и развитие лесных культур сосны в брусничном типе условий местопроизрастания}

\author{
А. Л. Юрьева ${ }^{1}$ \\ Петрозаводский государственный университет
}

\begin{abstract}
АННОТАЦИЯ
Статья посвящена изучению периодичности роста и развития сосны обыкновенной и ее зависимости от подготовки почвы и вида посадочного материала.
\end{abstract}

Ключевые слова: лесные культуры, ритмы роста, саженцы, сосна обыкновенная.

\section{SUMMARY}

This paper contains materials about periodical growth and development of Scots pine (Pinus sylvestris), dependence it on site preparation and kind of planted materials.

Keywords: reforestation, growth rhythms, seedlings, Scots pine (Pinus sylvestris).

Лесные культуры закладываются различными методами, с разными способами подготовки почвы, из различных видов посадочного материала. В Скандинавии накоплен опыт создания лесных культур посадкой сеянцев с закрытой корневой системой по неподготовленной почве. В нашей стране чаще используется посадочный материал с открытой корневой системой по подготовленной почве, но применяются и контейнеризированные сеянцы. Среди лесных культур, созданных в Карелии посадочным материалом с закрытой корневой системой, отмечены как успешные, так и неудачные (например, в условиях открытых болот и на побережье Ладожского озера в Питкярантском и Сортавальском районах). Они имели слаборазвитую деформированную корневую систему [4]. По-видимому, не все типы условий произрастания подходят для такого посадочного материала. В литературе отмечается, что для успешного укоренения сосны с закрытыми корнями почва должна быть хорошо дренируемая, тогда образуется стержневая корневая система, обеспечивающая высокую устойчивость растений $[1$, 2].

Таким образом, появилась необходимость в изучении особенностей роста контейнеризированных сеянцев и в разработке рекомендаций по их применению. Также нужно сравнить их развитие с развитием сеянцев с открытой корневой системой для выбора наиболее

\footnotetext{
${ }^{1}$ Автор - соискатель кафедры лесного хозяйства, преподаватель

(С) А. Л. Юрьева, 2003
}

экологически и экономически выгодного посадочного материала.

В 1999-2002 годах проводились исследования особенностей роста лесных культур сосны обыкновенной, созданных на вырубке десятилетней давности в брусничном типе условий местопроизрастания. Изучались культуры следующих вариантов:

1) созданные посадкой однолетних сеянцев сосны с закрытой корневой системой (ЗКС) с подготовкой почвы; 2) созданные посадкой однолетних сеянцев сосны с закрытой корневой системой без подготовки почвы; 3) созданные посадкой двулетних сеянцев сосны с открытой корневой системой (ОКС) с подготовкой почвы.

В каждом варианте измерялись следующие показатели: высота, длина главного корня, протяженность боковых корней, число боковых корней, диаметры у корневой шейки и на середине годичного прироста, длина, ширина и число хвоинок, сырая и сухая масса хвои, стволиков и корней.

Практически по всем измеряемым показателям в 1999 - 2002 гг. лидируют саженцы с закрытой корневой системой с подготовкой почвы (рис. 1). Приживаемость лесных культур выше у этого же варианта. Нужно отметить, что приживаемость саженцев с ЗКС без подготовки почвы была самой низкой (рис. 2a) среди вариантов, поэтому на второй год весной здесь проведено дополнение.

Анализ достоверности различий в 1999 - 2000 гг. показывает, что:

- саженцы с ОКС и с ЗКС с подготовкой почвы развиваются практически одинаково;

- у саженцев с ЗКС без подготовки почвы развитие в первый год после посадки идет медленнее, чем у остальных вариантов. К концу второго сезона роста достоверными остаются различия по четырем показателям (высоте, диаметру корневой шейки и осевого побега, числу хвоинок), то есть саженцы с ЗКС без подготовки почвы постепенно начинают догонять в росте саженцы, посаженные по двум другим вариантам.

Анализ различий в 2001-2002 гг. показывает:

- их достоверность между саженцами с ЗКС с подготовкой и без подготовки почвы по всем, кроме двух показателей (длина и ширина хвои);

- достоверность различий между саженцами с ОКС и ЗКС без подготовки почвы практически по всем показателям на конец сезона вегетации в 2001 г. и в течение всего сезона вегетации в 2002 г.;

- достоверность различий по некоторым показателям между саженцами с ОКС и с ЗКС с подготовкой почвы на конец сезона вегетации в 2001 г.;

- достоверность различий по высоте и диаметрам корневой шейки и осевого побега между саженцами с ОКС и с ЗКС с подготовкой почвы в течение всего вегетационного периода в 2002 г., а по остальным показателям на конец сезона. 

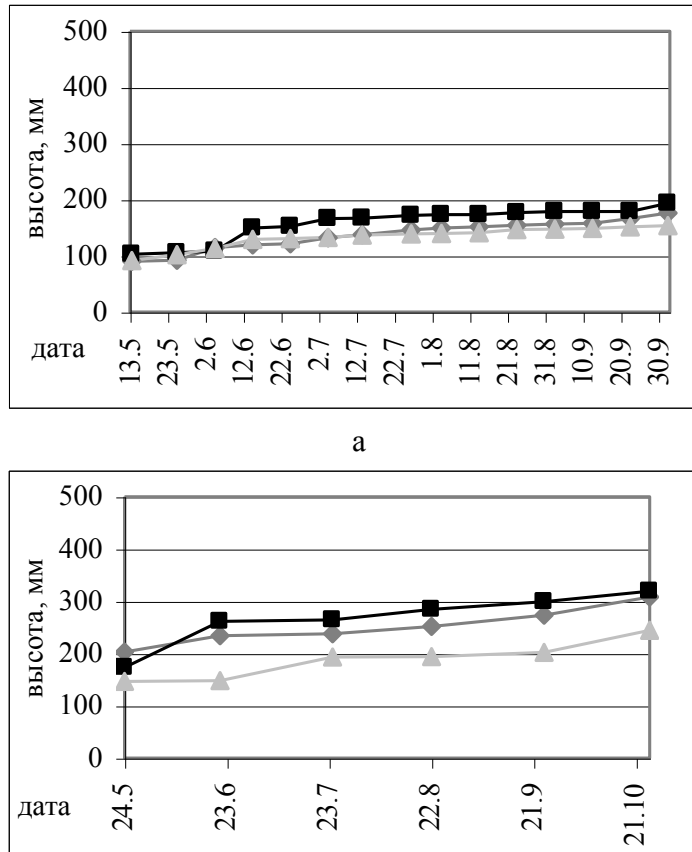

б
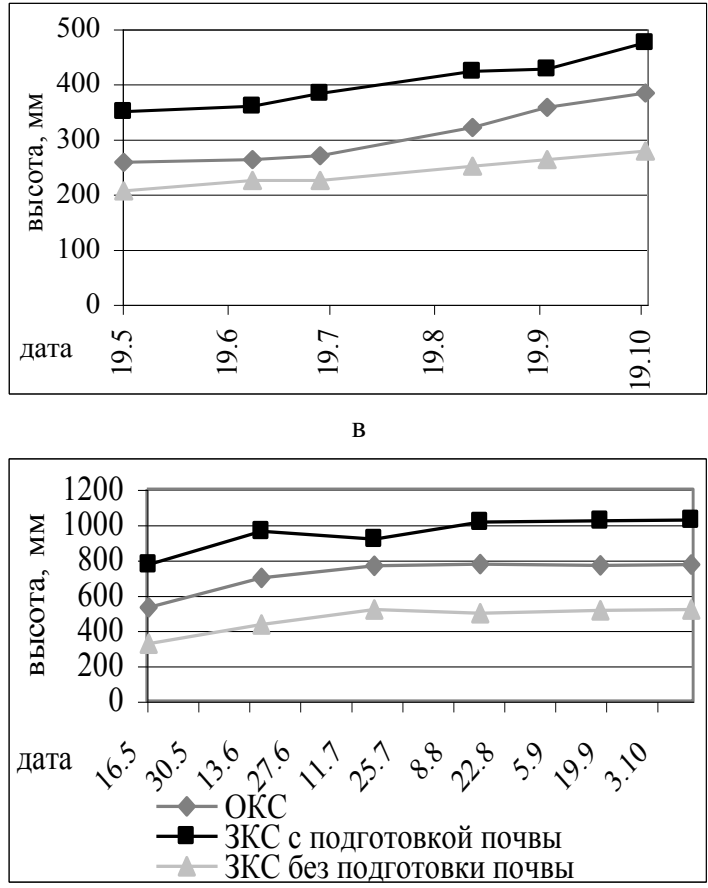

$\Gamma$

Рис. 1. Изменение высоты стволиков в 1999-2002 гг.

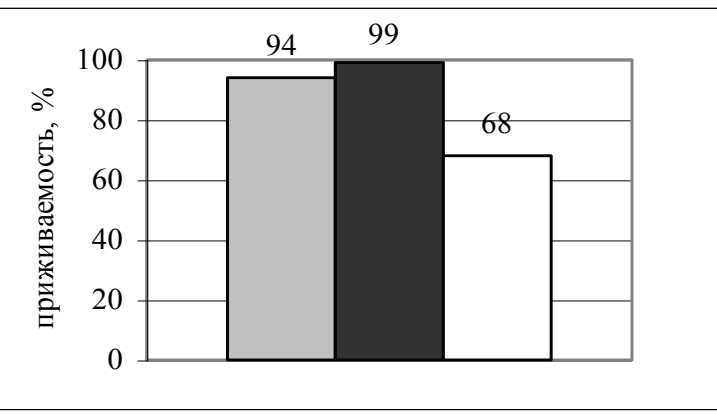

a
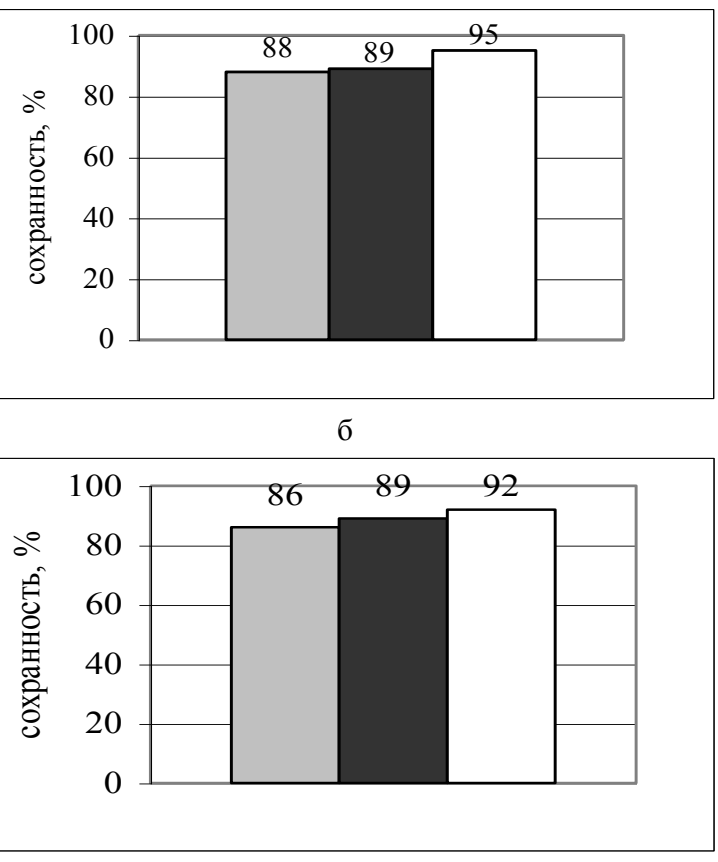

B

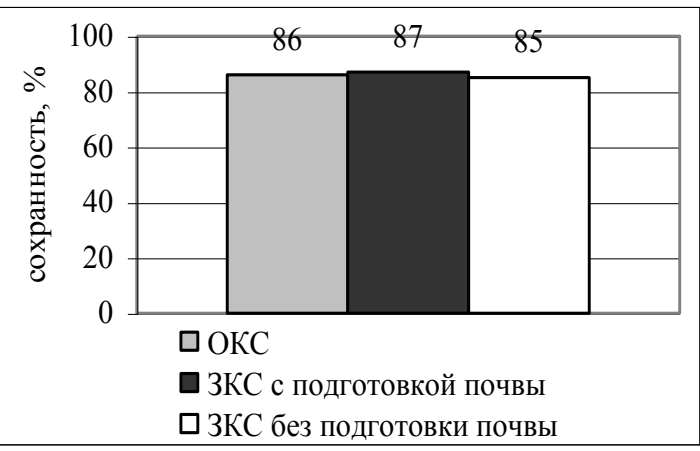

Рис. 2. Сохранность лесных культур в 1999-2002 гг. 
Итак, к концу 2000 г. саженцы с ЗКС без подготовки почвы постепенно догоняют в росте саженцы, посаженные по двум другим вариантам. Но наметившаяся тенденция не подтверждается в 2001-2002 гг. Саженцы без подготовки почвы намного отстают в развитии практически по всем показателям в течение всего сезона роста. На конец вегетации в 2002 г. между саженцами с ЗКС без подготовки почвы и по двум другим вариантам различия достоверны по всем показателям, кроме длины и ширины хвои. Полученные данные свидетельствуют о сильном влиянии подготовки почвы на рост и приживаемость культур. В нашем случае это влияние становится более заметно на четвертый год после посадки, т.е. усиливается со временем, хотя по многочисленным исследованиям [1] различия в росте лесных культур с возрастом сглаживаются.

В 1999 - 2001 гг. саженцы с ОКС и с ЗКС с подготовкой почвы развиваются практически одинаково, но в 2002 г. различия по высоте и диаметрам корневой шейки и осевого побега достоверны в течение всего сезона, а по остальным показателям достоверность подтверждается на конец сезона вегетации.

Сосна, в отличие от ели, не образует придаточных корней, поэтому любые повреждения корневой системы приводят к сильному ослаблению сеянцев, а иногда и к их гибели [2]. У растений с ЗКС риск повреждения корней ниже, чем у сеянцев с открытой корневой системой. Наличие кома питательного субстрата также обеспечивает лучший рост саженцев с ЗКС $[1,3]$. Возможно, эти факторы и сказались на лучшем развитии саженцев с ЗКС на четвертый год по сравнению с саженцами с ОКС.
Итак, посадочный материал с ЗКС имеет лучшие показатели роста и приживаемости по сравнению с ОКС. Также, исходя из приведенных данных, можно говорить о значительной роли, которую играет подготовка почвы в первые годы после посадки. Конечно, на основании четырехлетних исследований нельзя делать окончательные выводы о необходимости подготовки почвы при использовании посадочного материала с закрытой корневой системой. Но если в последующие годы саженцы с ЗКС будут попрежнему лидировать в росте, то можно говорить о целесообразности этой трудоемкой и дорогостоящей операции в условиях брусничного типа леса по супесчаным почвам.

\section{СПИСОК ЛИТЕРАТУРЫ}

1. Жигунов А. В. Теория и практика выращивания посадочного материала с закрытой корневой системы / СПбНИИЛХ. СПб., 2000. 293 с.

2. Изверкова И. М. О развитии корневой системы контейнеризированных сеянцев сосны и ели в культурах // Восстановление и мелиорация лесов Карелии: Сб научных трудов. Л., 1983. С. 55-60.

3. Козлова Т. И. Влияние последствий деформаций корней ПМЗК сосны на их регенерацию и последующий рост в культурах // Сосновые леса России в системе многоцелевого лесопользования: Тезисы всероссийской конференции ВЛТИ. Воронеж, 1993. С. 90-92.

4. Лесовосстановление на Европейском Севере: Материалы финско-российского семинара по лесовосстановлению. Финляндия 28 сентября - 2 октября 1998. Вуокатти, 2000. 